\title{
PROFESSOR FAUZER SIMÃO ABRÃO
}

Faleceu no dia 28 de novembro de 2008, na cidade de São Paulo, aos 75 anos, o Dr. Fauzer Simão Abrão, professor titular do departamento de Ginecologia e Obstetrícia da Faculdade de Medicina de Santo Amaro (UNISA). O Professor Fauzer graduou-se pela Escola Paulista de Medicina em 1959, desenvolveu sua carreira assistencial e acadêmica no Hospital A.C. Camargo, da Fundação Antônio Prudente (atual Hospital do Câncer), onde foi diretor do departamento de Ginecologia, e na Escola Paulista de Medicina (Unifesp). Obteve o título de mestre e doutor pela Unifesp, respectivamente, em 1987 e 1988. Dentro da linha de pesquisa de câncer ginecológico, o professor Fauzer recebeu diversos prêmios, foi homenageado, orientou teses de mestrado, deu conferências em congressos nacionais e internacionais, foi autor de livros, artigos científicos e participou da formação direta de inúmeros residentes e alunos na Unisa, onde se tornou professor titular em 1998.

Numa inversão de papéis, convivi por muitos anos com o paciente Fauzer Abrão. Frente à perspectiva nem sempre boa da doença, condição em que muitos se deixam levar pela

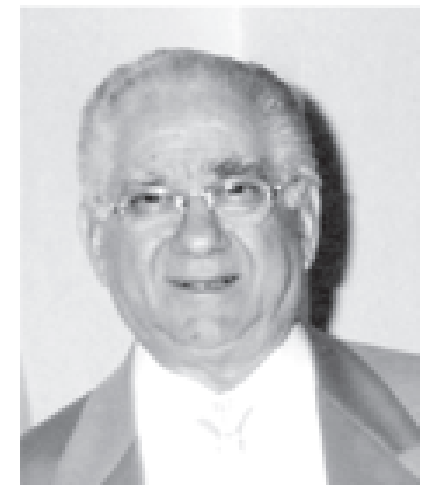

impaciência, irritabilidade e desesperança, Fauzer sempre me impressionou pela vontade, alegria de viver e bom humor. Não tive o prazer de ser seu aluno, mas pude aprender com ele. Espero transmitir suas lições a meus alunos e filhos. Adeus Professor Fauzer. 